\title{
Editorial
}

\section{Air Pollution, Air Quality, and Climate Change}

\author{
Sachin D. Ghude, ${ }^{1}$ Pavan S. Kulkarni, ${ }^{2}$ D. M. Chate, ${ }^{1}$ Mrinal Biswas, ${ }^{3}$ \\ Samir Pokhrel, ${ }^{1}$ and Anne Boynard ${ }^{4}$ \\ ${ }^{1}$ Indian Institute of Tropical Meteorology, Dr. Homi Bahbha Road, Pashan, Pune, India \\ ${ }^{2}$ Geophysics Centre of Evora (CGE), University of Evora, 7000 Evora, Portugal \\ ${ }^{3}$ National Center for Atmospheric Research, Boulder, CO, USA \\ ${ }^{4}$ Laboratoire Atmosph Ã'lres, Milieux, Observations Spatiales, Guyancourt, France \\ Correspondence should be addressed to Sachin D. Ghude; sachinghude@tropmet.res.in
}

Received 28 May 2014; Accepted 28 May 2014; Published 6 July 2014

Copyright (c) 2014 Sachin D. Ghude et al. This is an open access article distributed under the Creative Commons Attribution License, which permits unrestricted use, distribution, and reproduction in any medium, provided the original work is properly cited.

The introduction of gases and particulate contaminants in the atmosphere due to natural or human activities causes air pollution. The concentration and toxicity of these contaminants define air quality and in the long term contribute to climate change. Both air pollution and climate change influence each other through complex interactions in the atmosphere. This issue has 9 very interesting manuscripts, touching various aspects of air pollution and air quality and their impact on climate change.

Five out of nine articles deal with aerosols studies and their contribution to air pollution, radiative transfer, and cloud properties. B. P. Singh et al. studied the effect of burning of crackers and fireworks during festive season of Diwali on aerosol properties. They found significant increase in the aerosol optical depth, aerosol absorption coefficients, and aerosol scattering coefficients during affected period as compared to nonaffected periods. S. Tiwari et al. analyzed interannual and intraseasonal variability of aerosols, particularly fine mode particles $\left(\mathrm{PM}_{2.5}\right)$ at a dense traffic intersection and in the vicinity of a thermal power plant in the megacity of Delhi, India. They observed that during the study period $\mathrm{PM}_{2.5}$ concentration exceeds Indian National Ambient Air Quality Standards (NAAQS) on significant number of days. They also found the strong influence of different seasons and meteorological parameters on the concentration of $\mathrm{PM}_{2.5}$. A. S. Panicker et al. used satellite data to study the effect of aerosols on UV erythemal dose over megacities of Delhi, Mumbai, Kolkata, and Chennai in India. S. N. Pereira et al. analyzed time series of aerosol absorption coefficient over Evora, Portugal. They observed a strong annual cycle in aerosol absorption coefficient with high values during winters compared to summers. They noted that it may have resulted due to the combination of several factors, with emphasis on use of biomass (wood) burning for domestic heating during winters and lower boundary layer height restricting atmospheric dispersion of aerosols. W.-S. Jung et al. analyzed satellite data to study the seasonal variability of aerosol-cloud properties and aerosol indirect effect over four different regions in Korean Peninsula during the period 2000-2009. They also estimated aerosol indirect effect for summer monsoon period to find the role in modulating precipitation. S. Dipu et al. used zenith sky transmittance and surface radiation measurements to improve the retrieval of cloud microphysical parameters and found them in good agreement with the satellite data. D. M. Lal et al. used satellite data of lightning flashes and cloud ice size during the period 2000-2012 to study the interrelation between the two. They observed that total lighting increases with increase in the cloud ice size and attends maximum at certain optimum cloud ice size and after that lightning decreases with increasing cloud ice size. S. K. Kharol et al. in their manuscript reported long-term rainfall trends during summer monsoon over six major Indian cities. They also analyzed the variation in precipitation in the upwind and downwind directions to study the urban forcing and dynamics. F. B. Vicente et al. studied the effect of wildfires in Mexico and estimated 
total yearly emissions of $\mathrm{CO}_{2}$ in Mexico during the period 1999-2010 due to wildfires.

Through this special issue on air pollution, air quality, and climate change, we tried to bring forth the current issues in the field of air pollution and climate change.

Sachin D. Ghude

Pavan S. Kulkarni

D. M. Chate

Mrinal Biswas

Samir Pokhrel

Anne Boynard 

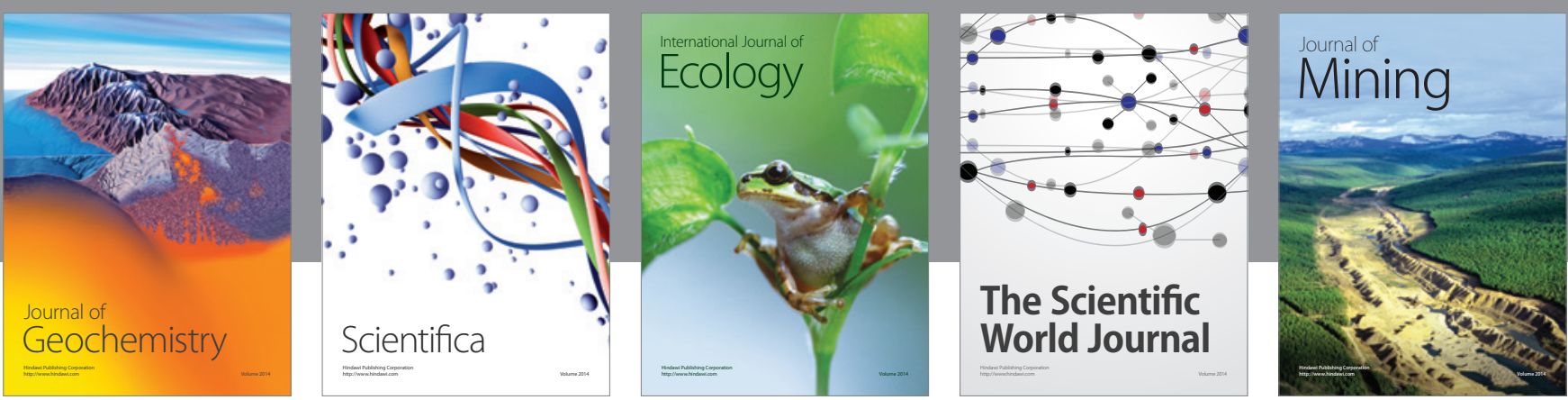

The Scientific World Journal
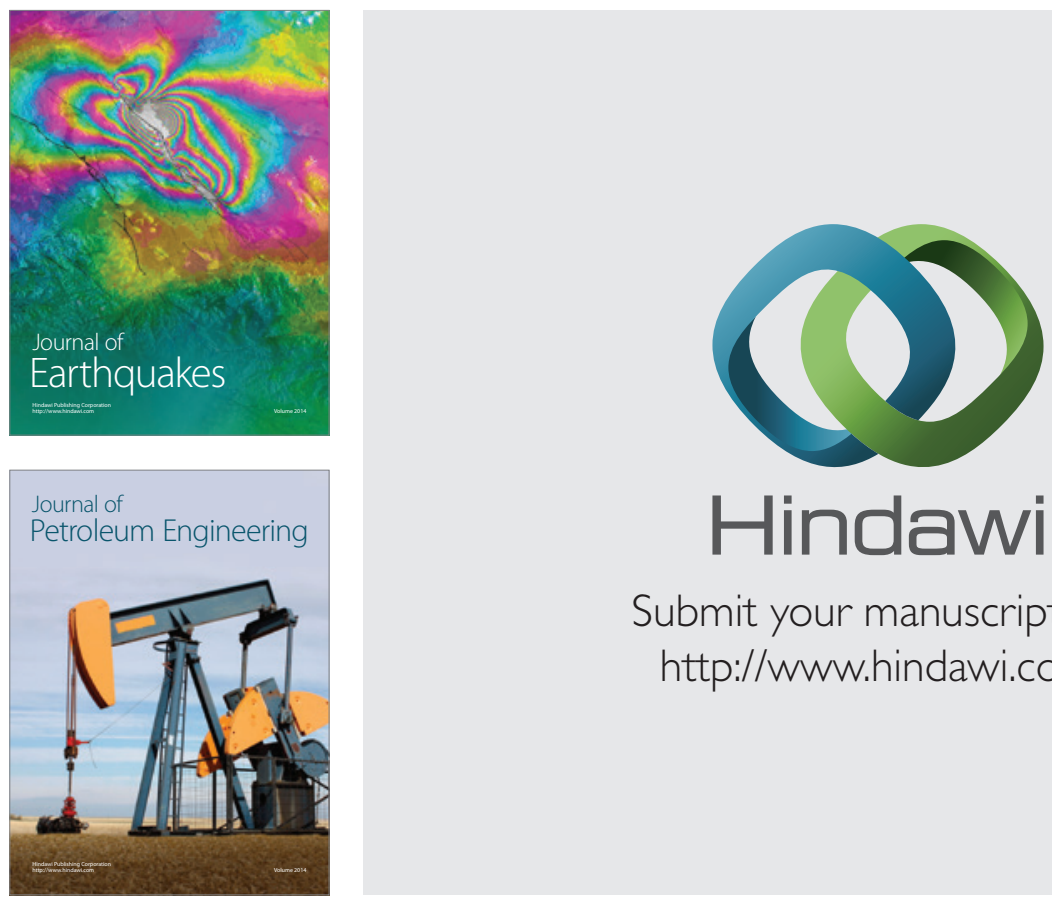

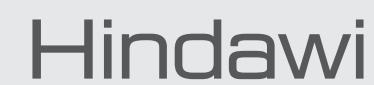

Submit your manuscripts at

http://www.hindawi.com
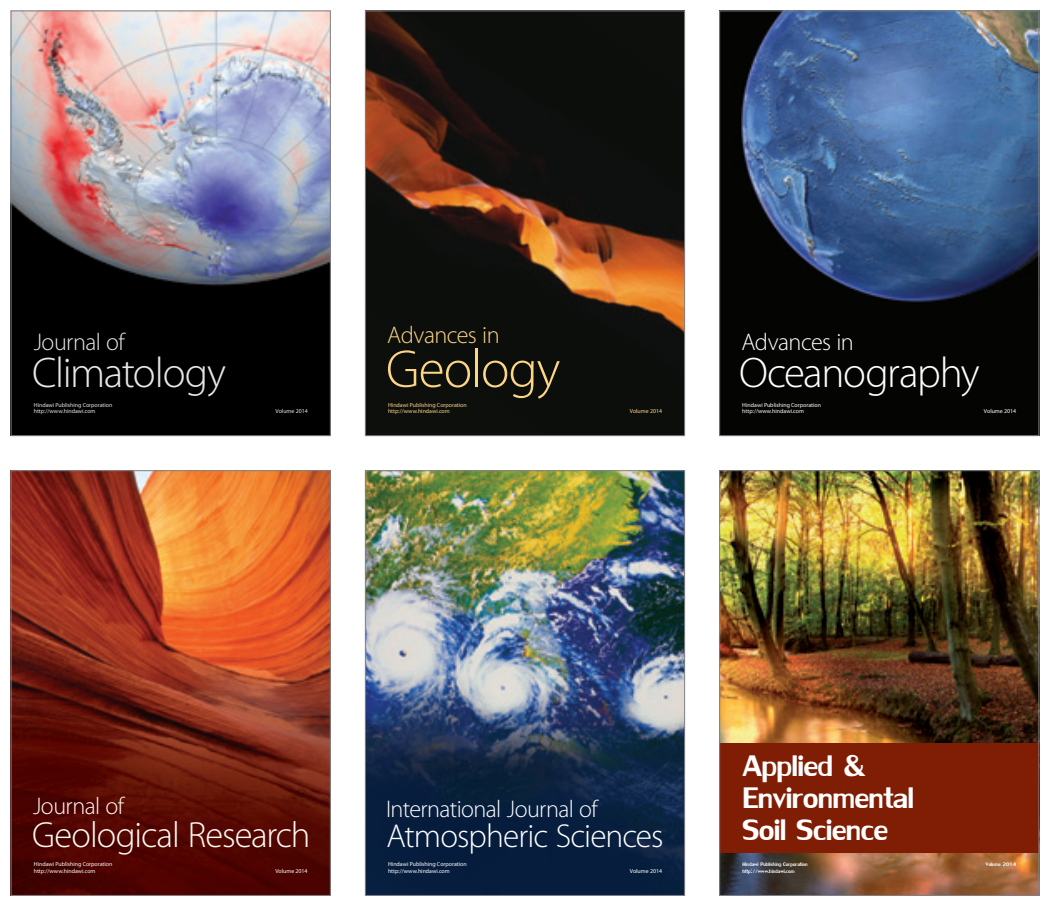
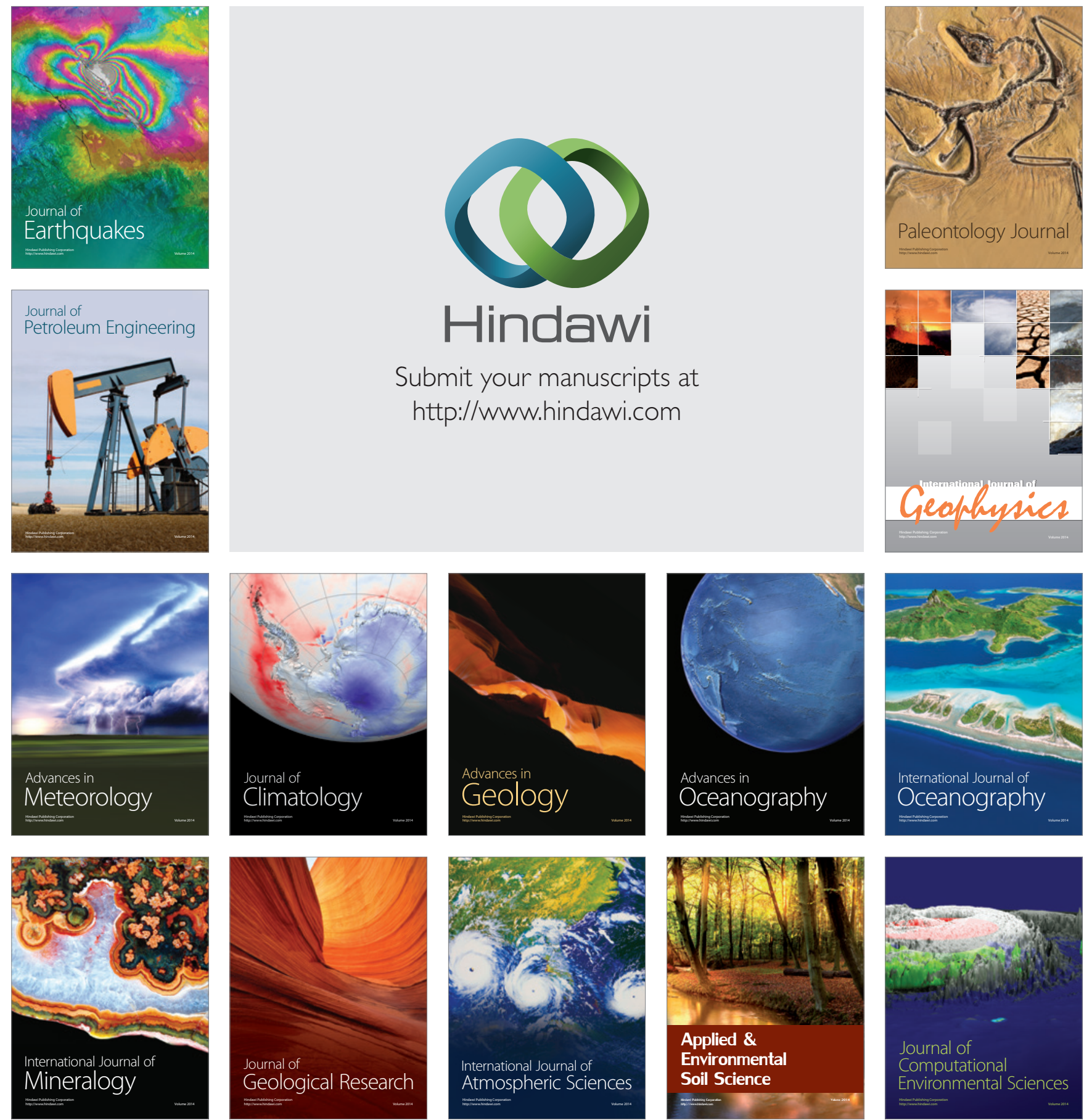